\title{
The role of Eph/ephrin molecules in stromal-hematopoietic interactions
}

\author{
Thao M. Nguyen ${ }^{1,2}$ Agnieszka Arthur ${ }^{1,2,3} \cdot$ Stan Gronthos ${ }^{1,2}$
}

Received: 1 October 2015 / Accepted: 5 October 2015 / Published online: 16 October 2015

(C) The Japanese Society of Hematology 2015

\begin{abstract}
Bone marrow mesenchymal stromal/stem cells (BMSC) are fundamental regulatory elements of the hematopoietic stem cell niche; however, the molecular signals that mediate BMSC support of hematopoiesis are poorly understood. Recent studies indicate that BMSC and hematopoietic stem/progenitors cells differentially express the Eph cell surface tyrosine kinase receptors, and their ephrin ligands. Eph/ephrin interactions are thought to mediate cross-talk between BMSC and different hematopoietic cell populations to influence cell development, migration and function. This review summarizes Eph/ephrin interactions in the regulation of BMSC communication with hematopoietic stem/progenitor cells and discusses Eph/ephrintargeted therapeutic strategies that are currently being pursued for various hematotological malignancies.
\end{abstract}

Keywords Haematopoietic stem cells niche $\cdot$ Bone marrow mesenchymal/stem cells $\cdot$ Stromal cells $\cdot$ Eph receptors $\cdot$ Ephrin ligands

Stan Gronthos

stan.gronthos@adelaide.edu.au

1 Mesenchymal Stem Cell Laboratory, School of Medicine, Faculty of Health Sciences, University of Adelaide, Adelaide, SA 5000, Australia

2 South Australian Health and Medical Research Institute, Adelaide, SA 5000, Australia

3 Division of Haematology, SA Pathology, Adelaide, SA 5000, Australia

\section{Eph and ephrin molecules}

Eph receptors are the largest family of tyrosine kinases first identified in the erythropoietin-producing hepatocellular (Eph) carcinoma cell line in 1987 by Hirai and colleagues [1], while their cognate ligands, the eph receptor interacting proteins, were termed ephrin molecules (also designated as Efn molecules) [2]. There are sixteen Eph receptors (EphA1-A10 and EphB1-B6) and nine ephrin ligands (ephrinA1-A6 and ephrinB1-B3) [2, 3] (Fig. 1). The receptors are divided into the $\mathrm{A}$ or $\mathrm{B}$ subclasses based on their binding affinity for their respective ligands. The structural homology is maintained between the Eph receptors of both subclasses; they are composed of extracellular and cytoplasmic components [2]. The extracellular portion of the Eph receptor consists of an amino terminal ligand binding domain, a cysteine-rich region and two fibronectin type III repeats [4]. The cytoplasmic region of the Eph receptor contains SRC homology 2 binding sites, a juxtamembrane region, a tyrosine kinase domain, a sterile alpha motif (SAM) protein-protein interaction domain, and a post-synaptic density, disc large, zona occludens-1 (PDZ) binding motif [5]. Each region is important in activating various signalling cascades and mediating a number of downstream events including cell shape, attachment, migration, proliferation, differentiation [6-9]. The Eph receptors signal and mediate these responses through tyrosine phosphorylation and protein-protein interactions. Binding of the ephrin ligand to the globular domain of the Eph receptor causes the autophosphorylation of the two kinases within the juxtamembrane domain, resulting in a conformational change of the juxtamembrane domain, exposing the kinases of the intracellular tyrosine kinase domain and converting it to an "active form" that can activate or repress downstream signalling cascades. Conversely, protein-protein interactions within the SAM domain 
Fig. 1 The structure of the Eph receptors and their ephrin binding ligands. Eph receptors are transmembrane proteins, consisting of a cysteine-rich region, fibronectin type III repeats, juxtamembrane, kinase, SAM and PDZ binding motif domains. The ephrin-B ligands are also transmembrane proteins while the ephrin-A ligands are GPI-anchor proteins. Forward signalling is through the cell expressing the Eph receptor whereas reverse signalling is via the cell expressing the ephrin ligand. GPI glycosyl phosphatidylino-sitol, $P D Z$ post-synaptic density, disc large, zona occludens-1, FNIII fibronectin III, SAM sterile alpha motif



and PDZ domain at the carboxyl terminus of the receptor can function independently of kinase phosphorylation [10].

The ephrin ligands are sub-divided into two groups based on their structure, the ephrin-A and ephrin-B [11]. The ephrin-A ligands are GPI linked to the membrane, where the GPI anchor is composed of one molecule of phosphatidylinositol, which has a carbohydrate chain link through the C-6 hydroxyl of the inositol. The GPI anchor functions to attach the ephrin-A ligand to the exoplasmic leaflet of the membrane and to other specific domains inside the cell [10]. Conversely, ephrin-B ligands are transmembrane proteins with a short cytoplasmic tail, which contains functional tyrosine kinase phosphorylation sites and an intracellular PDZ binding motif [12].

The Eph family of molecules is unique in that both the Eph receptor and ephrin ligand can act as either a receptor or a ligand, and in many situations, they can also act as both [13]. Forward signalling is mediated through the Eph receptor, whereas reverse signalling is mediated through ephrin ligand [10]. Bi-directional signalling involves the simultaneous activation of both the Eph receptor and the ephrin ligand upon Eph/ephrin binding and initiates downstream signalling pathways into the respective Eph and ephrin expressing cells [13]. The unique characteristic of the Eph/ephrin family is their binding ability. The receptors and ligands of both subclasses bind with varying affinity and promiscuity within each subclass and limited binding between subclasses [2, 14] (Fig. 2). Eph/ephrin molecules function through cell to cell interactions [2] where their signalling is crucial in developmental cell positioning [15], tissue and organ patterning [16], post-natal stem cell niche maintenance within the brain, intestine, skin, skeletal muscle, tooth [9, 14, 17], bone [7, 8, 18] and hematopoietic tissues [19-28].

\section{Eph and ephrin molecules expressed by hematopoietic stem/progenitor cells}

Human haematopoietic stem cells (HSC) are identified by the lack of cell surface markers that are normally present on lineage committed hematopoietic cells, while still expressing specific antigens such as CD34 that assist in the isolation of purified HSC [29]. Primitive human HSC $\left(\mathrm{CD}_{3} 4^{+} /\right.$ $\mathrm{CD}^{-} 8^{-} / \mathrm{Lin}^{-}$) are a highly enriched population capable of repopulating the hematopoietic system of SCID and NOD-SCID mice [30]. In the adult mouse, repopulating HSC are also defined by the lack of cell surface markers that are normally present on lineage committed cells, while still expressing high levels of stem cell-antigen-1 $\left(\mathrm{Scal}^{+}\right)$, stem cell factor ligand, $\mathrm{c}-\mathrm{Kit}^{+}$, and signalling lymphocytic activation molecule, CD150 ${ }^{+}$, but lacking CD48 expression [31-34]. Whilst the Eph receptor tyrosine kinase family was first identified in the hematopoietic system, it has only really been in the last decade that they have been interrogated for their potential role in hematopoietic stem/progenitor cell development and function, both in humans and mice [19, 21, 24, 26, 27].

Various Eph and ephrin molecules of both subclasses have been detected on human and mouse myeloid, erythroid, lymphoid populations and platelets $[19,22,23,25,27,35$, 36]. These molecules have been implicated in a number of processes relating to progenitor cell adhesion, migration, differentiation [23, 27], co-stimulation of $\mathrm{T}$ cell receptor 
Fig. 2 Binding affinity between Eph and ephrin molecules. The largest receptor tyrosine kinase family comprising 10 EphA and 6 EphB receptors, 5 ephrin-A and 3 ephrin-B (Efn) ligands. Promiscuous binding occurs between receptors and ligands within each subclass while there is limited binding between subclasses, with the exception of EphA4, which can bind to ephrin-B1-B2, and EphB2 which can interact with ephrin-A5

\section{Eph Receptors}

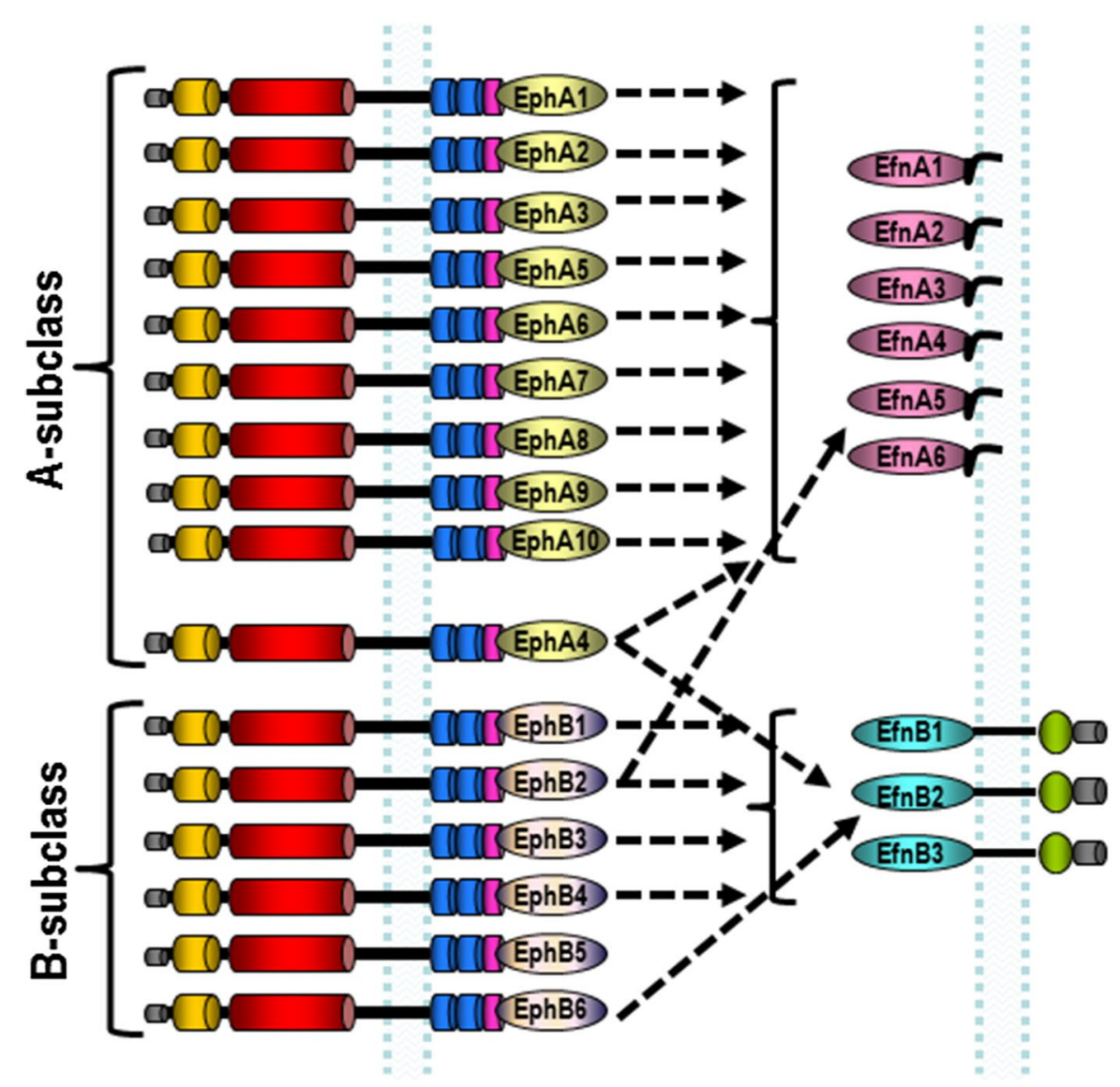

complex [37-39], B-cells communication to dendritic cells [40], and platelet activation and aggregation [41]. Other studies have reported the expression of different Eph and ephrin molecules by both human and mouse hematopoietic progenitor cell populations (Table 1). Gene expression analyses have identified high expression levels of EphA1, ephrin-A2, ephrin-A3 and ephrin-B2 by purified human bone marrow CD34 ${ }^{+}$HSC [42-44], whereas protein analyses demonstrated EphA2 and EphB2 expression on human mobilized peripheral blood CD $34^{+}$HSC [20]. Furthermore, EphB4 has been detected on human HSC isolated from umbilical cord blood using flow cytometric analysis [27]. In mouse studies, EphA1-EphA5 and ephrin-A1-ephrin-A5 were shown to be expressed by hematopoietic progenitor cells isolated from the bone marrow using flow cytometric analysis and quantitative real-time PCR [26]. From these findings, it appears that Eph/ephrin expression varies on different hematopoietic stem/progenitor cell populations depending on location, differentiation state and tissue source. However, the functional consequences of differential Eph/ephrin expression have yet to be determined.

\section{Eph and ephrin molecules expressed by bone marrow stem/stromal cells}

Human BMSC are a non-hematopoietic adult multipotent stem cell clonogenic population defined by the immunophenotype STRO- $1^{\text {bright }} / \mathrm{CD} 106^{+} / \mathrm{CD} 146^{+} / \mathrm{CD} 14^{-} / \mathrm{CD} 31^{-} /$ $\mathrm{CD}^{-} 4^{-} / \mathrm{CD} 45^{-} /$Glycophorin- $^{-}$[45-48] that have the capacity to differentiate into osteoblasts, adipocytes, and chondrocytes and reconstitute a hematopoietic microenvironment when transplanted into ectopic sites in vivo [49-52]. A number of studies have also reported the prospective isolation of a highly purified population of BMSC from murine compact bone [53-56], which express Sca-1 but lack expression of hematopoietic and endothelial cell lineage markers.

Human BMSC express high levels of EphB1, EphB2, EphB4, ephrin-B1 and ephrin-B2 (Table 1; Fig. 3), where $\mathrm{Eph} /$ ephrin interactions are known to regulate bone remodelling between stromal cells and osteoclasts [7, 8, 18, 57-61]. Forward signalling through EphB4 promotes BMSC osteogenic differentiation, whereas reverse signalling via ephrin-B2 suppresses osteoclast differentiation by 
Table 1 Regulation of BMSC and HSC function by Eph/ephrin interactions

\begin{tabular}{|c|c|c|c|}
\hline Cell population & Eph/ephrin involvement & Biological function & Refs. \\
\hline Human cord blood CD $34^{+}$HPC & EphB4 & $\begin{array}{l}\text { EphB4 preferentially accelerates the differentiation } \\
\text { of HPC to erythroid cells in erythropoiesis }\end{array}$ & {$[27,42,43]$} \\
\hline Human BM CD $34^{+} \mathrm{CD} 133^{+} \mathrm{HPC}$ & EphA2, EphB2, EphB4 & $\begin{array}{l}\mathrm{CD} 34^{+} \mathrm{CD} 133^{+} \mathrm{HPC} \text { express EphA2, EphB2, } \\
\text { EphB4 }\end{array}$ & {$[20]$} \\
\hline Human $\mathrm{BM} \mathrm{CD} 34^{+} \mathrm{CD} 38^{-} \mathrm{HSC}$ & EphB4/ephrin-B2 & $\begin{array}{l}\text { Enhanced hematopoietic reconstitution following } \\
\text { bone marrow transplantation }\end{array}$ & [44] \\
\hline Mouse HPC & EphA3/ephrin-A5 & HPC adhesion and trafficking patterns & {$[26]$} \\
\hline \multirow[t]{4}{*}{ Human BMSC } & Ephrin-B1 & $\begin{array}{l}\text { Mutation of ephrin-B1 results in } \\
\text { Craniofrontonasal syndrome }\end{array}$ & {$[61]$} \\
\hline & $\begin{array}{l}\text { EphB1, EphB2, EphB4, } \\
\text { ephrin-B1, ephrin-B2, ephrin-B3 }\end{array}$ & $\begin{array}{l}\text { BMSC attachment, migration and osteochondral } \\
\text { differentiation }\end{array}$ & [8] \\
\hline & EphB4 & Enhanced hematopoietic support & [44] \\
\hline & EphB2, ephrin-B2 & Suppression of activated T-cells & {$[6]$} \\
\hline \multirow[t]{7}{*}{ Mouse BMSC } & EphA2 & $\begin{array}{l}\text { Suppression of osteoblastogenesis in the bone } \\
\text { remodelling initiation phase }\end{array}$ & {$[57]$} \\
\hline & EphB4 & Enhanced bone formation & {$[59]$} \\
\hline & EphB4 & Enhanced bone fracture repair & [7] \\
\hline & EphB4 & Enhanced stromal support of hematopoiesis & [44] \\
\hline & EphB4 & $\begin{array}{l}\text { Protected subchondral bone and cartilage during } \\
\text { osteoarthritis }\end{array}$ & {$[82]$} \\
\hline & Ephrin-B1 & Loss of ephrin-B1 reduced bone formation & {$[60]$} \\
\hline & Ephrin-B2 & $\begin{array}{l}\text { Interactions with PTH and PTHrP in bone } \\
\text { formation process }\end{array}$ & {$[58,67]$} \\
\hline
\end{tabular}

$H P C$ hematopoietic progenitor cells, $B M$ bone marrow, $P T H$ parathyroid hormone, $P T H r P$ parathyroid hormone-related proteins

Fig. 3 Human BMSC expression of EphB and ephrin-B molecules. Immunocytochemical staining of EphB/ephrin-B proteins (green) expressed by human ex vivo expanded BMSC, the cytoskeleton is defined by F-actin (red) staining, while the nucleus was stained with DPAI (blue), demonstrating the distribution of protein expression at the filapodia/lamelapodia and cytoskeleton. Scale Bar $20 \mu \mathrm{m}$
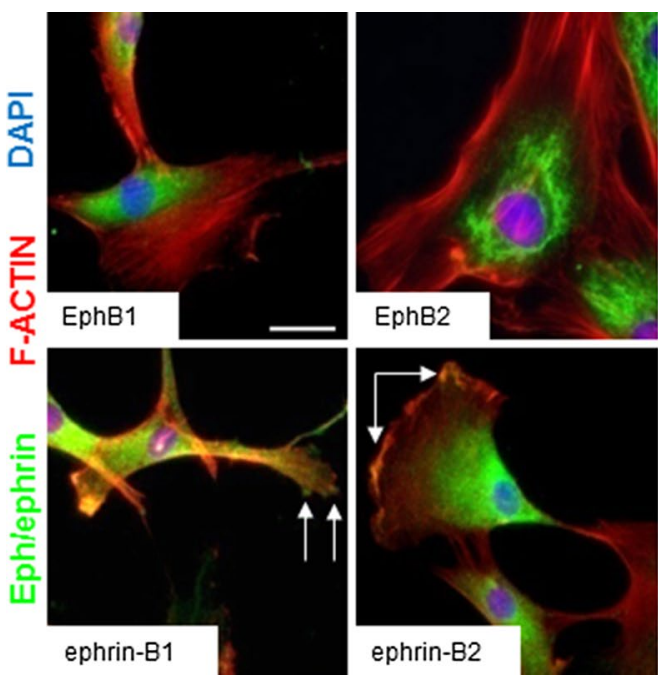
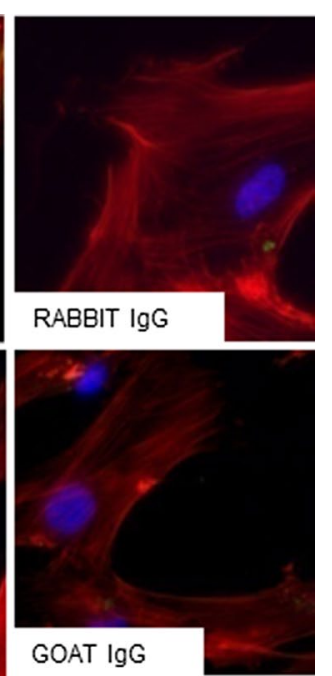

inhibiting the c-Fos-NFATc1 signalling cascade. While EphB4/ephrin-B2 interactions promote bone formation, other reports have shown that EphA2/ephrin-A2 bidirectional signalling appears to regulate bone remodelling at the initiation phase, particularly enhancing bone resorption [57]. Reverse signalling through ephrin-A2, expressed in early differentiating osteoclasts, enhanced osteoclastogenesis, most likely mediated by activation of phospholipase $\mathrm{C} \gamma 2$, whereas forward signalling through osteoblast-derived EphA2 suppressed osteoblastic bone formation and mineralization via activation of RhoA. The differences of bone resorption versus bone formation mediated by EphA2 and EphB4, respectively, could possibly due to the diversity of signalling activities. Forward signalling through EphA2 enhances RhoA activity resulting in inhibition of osteoblast differentiation, whereas signalling 
via EphB4 suppresses RhoA activity and, therefore, stimulates osteoblast differentiation $[18,57,59]$. However, it is still unclear how EphA2 and EphB4 differentially regulate RhoA activity. Eph/ephrin signalling appears to be highly complex and often results in diametrically opposing responses in cell adhesion/repulsion, proliferation, migration, apoptosis and tumour promotion/suppression [13, 62, $63]$. These cellular responses are thought to be dependent on cell type, differentiation state, tissue type, and the affinity of the Eph/ephrin pairings, which exhibit a high degree of promiscuity within and between the A and B subclasses.

Other molecules such as ephrin-B1 have been shown to be important for human BMSC maintenance and differentiation $[8,61,64-66]$. Loss-of-function mutations in ephrinB1 disturb tissue boundary formation at the developing coronal suture, resulting in shortening of the skull, a condition known as craniofrontonasal syndrome and other skeletal deformities [60, 61]. Another ephrin-B ligand, ephrinB2, expressed at lower levels in stromal cells, is regulated following activation of parathyroid hormone receptor 1 (PTHR1) in the presence of PTH, in a dose-dependent fashion, indicating a possible role for ephrin-B2 in the anabolic bone function of PTH [58, 67]. Collectively, these studies implicate different Eph/ephrin molecules in bone development/homeostasis, and stromal cell growth/differentiation, which are likely to have major consequences on the composition and function of the bone marrow HSC niche.

\section{EphB/ephrin-B mediated interactions between BMSC and HSC}

While a number of Eph/ephrin molecules have been identified on BMSC and HSC populations, the majority of studies have predominantly focused on the EphB4/ephrin-B2 interacting pair. Several studies have shown that EphB4 and ephrin-B2 regulate BMSC support of hematopoietic progenitor cells during erythropoiesis [23, 24, 27]. EphB4 expression has been detected on HSC isolated from human umbilical cord blood [23, 27], while ephrin-B2, the cognate ligand of EphB4, was found to be expressed on BMSC [21, 44]. In this context, EphB4/ephrin-B2 interactions resulted in an increased incidence of human cord blood CD34 ${ }^{+} / \mathrm{c}-\mathrm{kit}^{+} / \mathrm{EphB}^{+}{ }^{+} \mathrm{HSC}$ differentiation towards erythroid progenitor cells, correlating with the increased expression of glycophorin-A [23]. It was further confirmed that the interaction between EphB4 and ephrin-B2 during erythropoiesis was mediated through EphB4 forward signalling in cord blood CD34 ${ }^{+}$HSC [24]. Interestingly, EphB4 expression in HSC declined significantly after contact with an ephrin-B2 expressing stromal cell line [24]. These findings suggest that EphB4/ephrin-B2 interactions induced forward signalling within the EphB4 ${ }^{+} \mathrm{HSC}$, which triggered the detachment of the EphB4 ${ }^{+} \mathrm{HSC}$ from the ephrin-B2 expressing stromal cell layer. This detachment was proposed to increase exposure to soluble cytokines such as erythropoietin, leading to the differentiation of HSC into mature erythroid cell, implying that forward rather than bidirectional or reverse signalling was essential for the process of stromal cell support of erythropoiesis.

Conversely, EphB4 expressed by stromal cells modulates ephrin-B2 expression levels and subsequently affects transmigration of hematopoietic progenitor cells [21]. This study reported that ephrin-B2 expression levels by hematopoietic progenitor cells were significantly higher when co-cultured with EphB4 ${ }^{+}$compared with EphB4 ${ }^{-}$stromal cells, indicating that EphB4 expressing stromal cells play a role in inducing ephrin-B2 expression by hematopoietic progenitor cells. Of note, ectopic expression of ephrinB2 in the hematopoietic cell line, 70z/3, confirmed a significant decrease in the locomotive activity of hematopoietic cells underneath a stromal cell layer [21]. Moreover, disruption of EphB4/ephrin-B2 communication using an EphB4 peptide inhibitor or shRNA-mediated knockdown of EphB4 in BMSC reduced their capacity to support hematopoiesis in vitro [44]. In agreement with these findings, mouse BMSC derived from a transgenic EphB4 mouse model (EphB4Tg), under the control of the collagen type 1 promoter, exhibited an enhanced capacity to support HSC maintenance [44, 59]. The EphB4Tg mice exhibited a higher frequency of BMSC lineage cells including osteoprogenitors and osteoblasts, correlating with an increased clonogenicity of BMSC. Moreover, EphB4 over-expressing BMSC influenced the hematopoietic progenitor/stem cell compartment, resulting in a significant increase of hematopoietic stem/progenitor cell numbers both in vitro and in vivo [44]. Assessment of hematopoietic reconstitution following bone marrow ablation found that donor HSC, infused into irradiated mice, demonstrated increased levels of homing to the bone marrow and engraftment in recipient EphB4Tg mice compared to wild type littermates. Collectively, these findings imply that EphB4-ephrin-B2 interactions are important mediators of the HSC niche microenvironment. The molecular basis of the increased support of ephrin-B2 expressing HSC by EphB4 overexpressing BMSC was attributed, in part, to increased gene and protein expression levels of hematopoietic supportive factors such as CXCL12, Angiopoietin-1, IL-6, FLT-3 ligand and Osteopontin by EphB4 overexpressing BMSC [44], where CXCL12 has also been widely described as a key mechanism in HSC homing [68, 69]. Whilst further studies are required to determine the downstream signalling events mediating EphB4/ephrin-B2 BMSC-HSC communication, these findings have identified an important role for $\mathrm{EphB} /$ ephrin-B in BMSC-mediated support of hematopoiesis, offering potential new insights into the environmental factors essential for the regulation of HSC by BMSC. 


\section{EphA/ephrin-A interactions between BMSC and HSC}

The consequences of EphA/ephrin-A signalling during BMSC-HSC communications remain less explored than their EphB/ephrin-B counterparts due to the scarcity of knowledge on GPI-linked ephrin-A ligands which lack a cytoplasmic signalling domain $[13,70]$. Recently, the A subclass of Eph and ephrin molecules have been reported to influence the migration of hematopoietic progenitor cells, where ephrin-A5 enhanced HSC trafficking and adhesion patterns [26]. EphA3-mediated reverse signalling through ephrin-A5 influenced HSC adhesion via the VLA-4 ligand, integrin $\alpha_{4} \beta_{1}$ molecule (CD49d/CD29) to the extracellular matrix protein ligand, fibronectin and the immunoglobular superfamily member ligand, vascular cell adhesion molecule-1 (CD106) [26], known to be highly expressed by purified human BMSC prior to culture [45]. Indeed, the activation of ephrin-A5 signalling within HSC resulted in the phosphorylation of paxillin, a downstream effector of integrin function [26]. Integrins are proteins that mediate cell-cell and cell-matrix attachment within a tissue; their function is critical for HSC adhesion, proliferation and migration during hematopoietic development [71]. Moreover, HSC adhesion to BMSC has been reported to occur through integrin $\alpha_{4} \beta_{1} / \mathrm{CD} 106$-dependent mechanisms [72]. Therefore, activation of ephrin-A5 by EphA3 affected HSC adhesion through an integrin-mediated mechanism. Interestingly, an intraperitoneal injection of EphA3-fusion protein into mice enhanced the mobilization of HSC into the peripheral blood, whereas blocking EphA3/ephrin-A5 interactions by functional blocking peptides affected the in vivo homing properties of HSC [26]. Hence, ephrin-A reverse signalling plays a potential role in modifying the adhesive properties of HSC within the bone marrow niche via an integrin-mediated mechanism where activation of ephrin-A promoted HSC migration to the peripheral blood and inhibited HSC homing to their niche. These observations suggest a potential role for EphA/ephrin-A communication between HSC and BMSC. While these findings are compelling, it must be noted that ephrin-A5 is also known to interact with EphB2 [73], expressed by both murine and human BMSC $[8,59]$. Therefore, there may be a considerable diversity in the signalling activities mediated via ephrin-A5, where the involvement of EphB2/ephrin-A5 interactions in HSC maintenance remains to be demonstrated. Nevertheless, these findings have identified EphA/ephrin-A signalling as one potential mechanism regulating the migration of HSC within the hematopoietic microenvironment. Given that $\mathrm{HSC}$ reside in close proximity to BMSC within the bone marrow microenvironment [74], EphA/ephrin-A interactions may act as important mediators of cross-talk between BMSC and primitive HSC to maintain the stem cell pool and regulate blood cell production.

\section{Targeting Eph/ephrin interactions as therapeutic strategies for haematological malignancies}

The central role of Eph/ephrin signalling mechanisms in hematopoietic development and homeostasis has triggered mounting interest in exploring their role in a number of haematological conditions. The potential role of EphA/ ephrin-A signalling has recently been recognized in haematological malignancies including acute myeloid leukemia, chronic myeloid leukemia, chronic lymphocytic leukemia, myelodysplastic syndromes and myeloproliferative disorders [75-77]. The EphA3 receptor is highly expressed within the bone marrow microenvironment of human leukemia and mouse tumour xenografts; however, its expression is not detectable in the non-malignant microenvironment. This significant finding prompted the development of the agonistic anti-EphA3 antibody, mAb IIIA4, as an anti-cancer therapeutic. The IIIA4 mAb has been shown to trigger EphA3 activation leading to inhibition of tumour growth by disrupting the integrity and function of newly formed tumour stroma and microvasculature, resulting in tumour cell contraction, aggregation and apoptosis [75]. Further therapeutic development has resulted in a recombinant, defucosylated human immunoglobulin G1k (IgG1k) therapeutic mAb version (KB004; KaloBios Pharmaceuticals, California, USA) [78]. The KB004 antibody has displayed anti-tumour activity by targeting EphA3 ${ }^{+}$tumour stroma and vasculature to induce leukemic stem cell apoptosis. An ongoing phase I clinical trial over multiple centres is currently examining the clinical efficacy and safety of KB004 in treating various haematological diseases (ClinicalTrials.gov identifier number NCT01211691).

While anti-cancer agents targeting EphA/ephrin-A signalling in leukemia is in clinical trials, the role of EphB4 in multiple myeloma (MM) has also been investigated $[79,80]$. The haematological disease MM is a plasma cell malignancy caused by an elevated bone resorption by osteoclasts and reduced bone formation by osteoblasts, resulting in osteolytic lesions, fractures and hypercalcemia [81]. While EphB4/ephrin-B2 signalling between osteoblasts and osteoclasts is important for bone homeostasis [59], bone fracture repair [7] and osteoarthritis [82], EphB4 expression in myelomatous bones is diminished compared with healthy counterparts [80]. In an attempt to manipulate the EphB4/ephrin-B2 signalling in MM microenvironment, it was shown that EphB4-fusion protein $(\mathrm{EphB} 4-\mathrm{Fc})$ treatments in the humanised SCID (SCID-Hu) mouse model of MM resulted in an enhanced osteoblast number and subsequently bone formation while a reduction in osteoclast 
number was observed [80]. These findings are in agreement with that of Zhao et al. 2006 who demonstrated that EphB4/ephrin-B2 signalling is a critical mechanism for bone homeostasis [59]. Perhaps, MM cells-mediated downregulation of EphB4 expression in osteogenic cells may facilitate osteolytic disease via reduced bone formation and increased bone resorption through activation of osteoclasts. In support of this notion, EphB4-Fc treatment in MM of SCID-Hu mice showed a reduction in tumour burden. Most significantly, the anti-myeloma activity of EphB4 was not acting on MM cells but on human BMSC, confirming a MM cell-mediated imbalance of ephrin-B2/EphB4 signalling in the BMSC population. It is postulated that EphB4$\mathrm{Fc}$ exerts its modulatory effects on the bone marrow microenvironment of MM by inhibiting osteoclastogenesis and neovascularization, while promoting osteoblast activity. These findings may lead to a therapeutic approach to upregulate the endogenous expression of EphB4 in MM bone marrow microenvironment, perhaps by administration EphB4-Fc to suppress tumour burden and restore the balance of the bone coupling process in MM patients.

\section{Concluding remarks}

The significant role facilitated by the Eph and ephrin molecules in mediating BMSC support of hematopoietic progenitor and stem cells has raised the importance of Eph/ephrin in the regulation of the hematopoietic system under normal and malignant circumstances. A number of Eph and ephrin
Fig. 4 A schematic representation of Eph/ephrin interactions in BMSC-mediated support of hematopoietic progenitor/stem cell function. BMSC expressing ephrin-B2 promoted EphB4 expressing HPC differentiation into mature erythroid cells in erythropoiesis. EphB4, expressed by BMSC, enhanced BMSC support of HSC maintenance and hematopoietic reconstitution following bone marrow transplantation. EphA/ephrin-A interactions are involved in HPC mobilization and homing. Blocking EphA3 expression within the bone marrow microenvironment of leukemia using KB004 anticancer agent resulted in tumour cell apoptosis. Administration of EphB4-Fc reduced tumour burden and bone loss in multiple myeloma. $H P C$ hematopoietic progenitor cells, CXCL12 C-X-C motif chemokine 12, also known as stromal cell-derived factor 1 , Ang- 1 angiopoietin-1, $I L-6$ interleukin-6, LSC leukemic stem cell

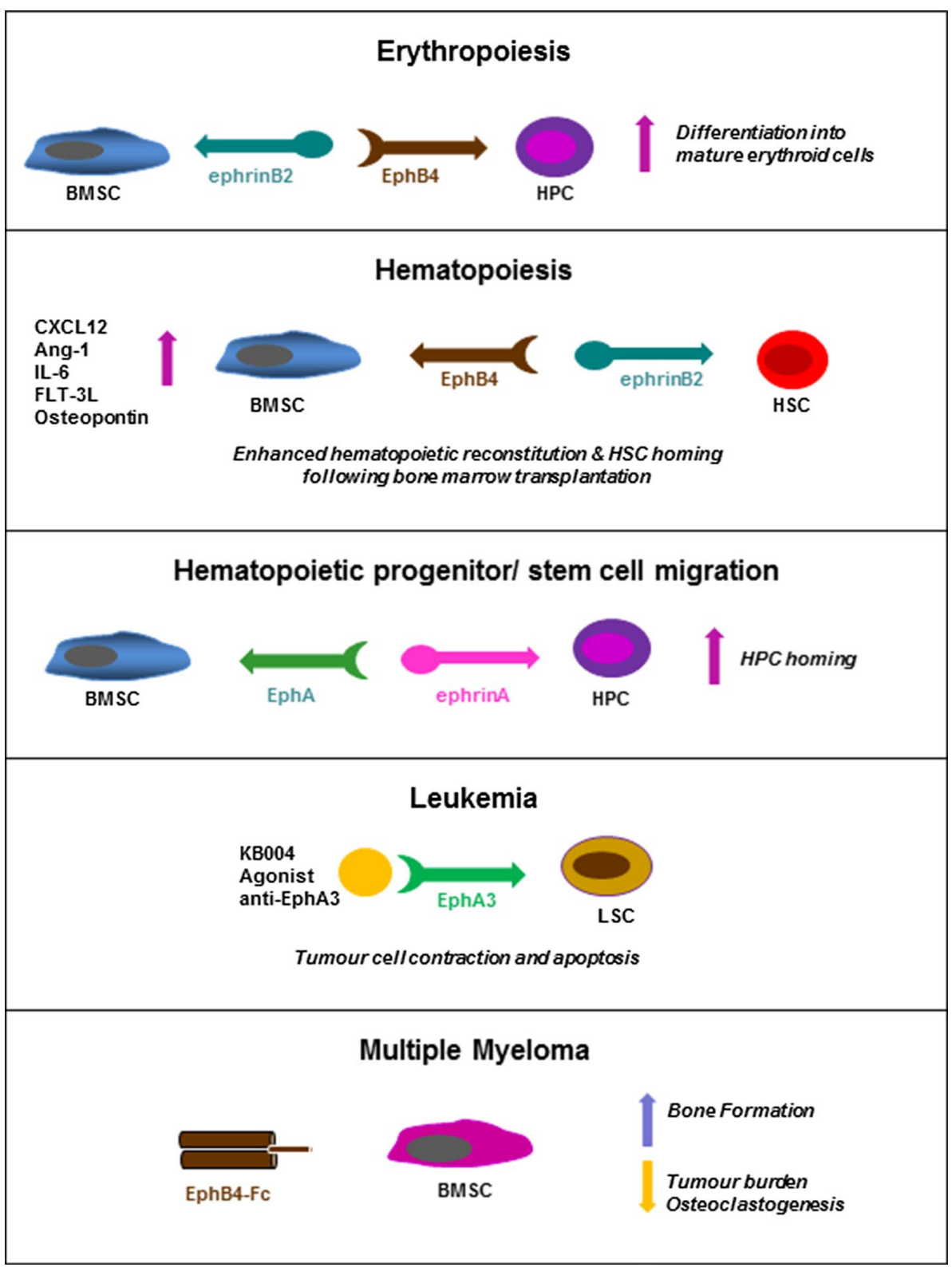


molecules have been reported as potential mediators (Fig. 4). However, BMSC and hematopoietic populations express a wide range of Eph/ephrin molecules and interacting partners owing to the large number of possible Eph/ephrin interactions due to their promiscuous binding nature; the impact mediated by Eph/ephrin molecules may vary for different situations. Therefore, further analyses are required to gain a more comprehensive understanding of the functional role of individual $\mathrm{Eph} / \mathrm{ephrin}$ molecule pairs used for communication between different BMSC-hematopoietic populations. Increased knowledge of these processes may lead to the development of therapeutic strategies that enhance HSC mobilization, homing and engraftment. Similarly, EphA3 expression within the bone marrow microenvironment may be exploited to disrupt the maintenance of localized leukemic stem cells (LSC). With increasing focus on targeting EphA3 as a promising anti-cancer therapy, further investigations into the underlying mechanisms of EphA3 action would be desirable. Similarly, MMmediated downregulation of EphB4 expression in BMSC appears to be a contributing factor to the severity of osteolytic disease and tumour burden. This significant finding may have therapeutic potential and further research would provide a better understanding of EphB4 involvement in MM. Collectively, these studies pave the way for targeting Eph/ephrin signalling involved in regulation of the HSC microenvironment, in order to influence clinical outcomes for various haematological malignancies and associated disorders.

Acknowledgments This work was supported by Royal Adelaide Hospital Mary Overton Fellowship and NHMRC Project Grant No. APP1083704.

\section{Compliance with ethical standards}

Conflict of interest The authors declare that they have no conflict of interest.

\section{References}

1. Hirai H, Maru Y, Hagiwara K, Nishida J, Takadu F. A novel putative tyrosine kinase receptor encoded by the eph gene. Science. 1987;238:1717-20.

2. Pasquale EB. The Eph family of receptors. Curr Opin Cell Biol. 1997;9(5):608-15.

3. Nagano K, S-i Kanasaki, Yamashita T, Maeda Y, Inoue M, Higashisaka K, et al. Expression of Eph receptor A10 is correlated with lymph node metastasis and stage progression in breast cancer patients. Cancer Med. 2013;2(6):972-7.

4. Kullander K, Klein R. Mechanisms and functions of Eph and ephrin signalling. Nat Rev Mol Cell Biol. 2002;3:475-86.

5. Himanen JP, Saha N, Nikolov DB. Cell-cell signaling via Eph receptors and ephrins. Curr Opin Cell Biol. 2007;19(5):534-42.

6. Nguyen TM, Arthur A, Hayball JD, Gronthos S. EphB and ephrin$B$ interactions mediate human mesenchymal stem cell suppression of activated T-cells. Stem Cells Dev. 2013;22(20):2751-64.

7. Arthur A, Panagopoulos RA, Cooper L, Menicanin D, Parkinson $\mathrm{IH}$, Codrington JD, et al. EphB4 enhances the process of endochondral ossification and inhibits remodeling during bone fracture repair. J Bone Miner Res. 2013;28(4):926-35.

8. Arthur A, Zannettino A, Panagopoulos R, Kobla S, Sims NA, Stylianou C, et al. EphB/ephrin-B interactions mediate human MSC attachment, migration and osteochondral differentiation. Bone. 2011;48:533-42.

9. Arthur A, Koblar S, Shi S, Gronthos S. Eph/ephrinB mediate dental pulp stem cell mobilization and function. J Dent Res. 2009;88(9):829-34.

10. Pasquale EB. Eph receptor signaling casts a wide net on cell behaviour. Nat Rev. 2005;6:462-75.

11. Pasquale EB. Eph-ephrin bidirectional signaling in physiology and disease. Cell. 2008;133(1):38-52.

12. Murai KK, Pasquale EB. 'Eph'ective signaling: forward, reverse and crosstalk. J Cell Sci. 2003;116:2823-32.

13. Pasquale EB. Eph receptors and ephrins in cancer: bidirectional signalling and beyond. Nat Rev Cancer. 2010;10(3):165-80.

14. Boyd AW, Bartlett PF, Lackmann M. Therapeutic targeting of EPH receptors and their ligands. Nature. 2014;13:39-62.

15. Furukawa K, Sato T, Katsuno T, Nakagawa T, Noguchi Y, Tokumasa A, et al. Smad3 contributes to positioning of proliferating cells in colonic crypts by inducing EphB receptor protein expression. Biochem Biophys Res Commun. 2011;405(4):521-6.

16. Gerety SS, Wang HU, Chen Z, Anderson DJ. Symmetrical mutant phenotypes of the receptor EphB4 and its specific transmembrane ligand ephrin-B2 in cardiovascular development. Mol Cell. 1999;4(3):403-14.

17. Stokowski A, Shi S, Sun T, Bartold P, Koblar S, Gronthos S. EphB/ephrinB interaction mediates adult stem cell attachment, spreading, and migration: implications for dental tissue repair. Stem Cells. 2007;25:156-64.

18. Matsuo K, Otaki N. Bone cell interactions through Eph/ephrin: bone modeling, remodeling and associated diseases. Cell Adhes Migr. 2012;6(2):148-56.

19. Aasheim HC, Delabie J, Finne EF. Ephrin-A1 binding to CD4+ $\mathrm{T}$ lymphocytes stimulates migration and induces tyrosine phosphorylation of PYK2. Blood. 2005;105(7):2869-76.

20. Lazarova P, Wu Q, Kvalheim G, Suo Z, Haakenstad KW, Meto$\operatorname{diev} \mathrm{K}$, et al. Growth factor receptors in hematopoietic stem cells: EPH family expression in CD34+ and CD133+ cell populations from mobilized peripheral blood. Int J Immunopathol Pharmacol. 2006;19(1):49-56.

21. Okubo T, Yanai N, Obinata M. Stromal cells modulate ephrinB2 expression and transmigration of hematopoietic cells. Exp Hematol. 2006;34(3):330-8.

22. Prévost N, Woulfe DS, Jiang H, Stalker T, Marchese P, Ruggeri $\mathrm{ZM}$, et al. Eph kinases and ephrins support thrombus growth and stability by regulating integrin outside-in signaling in platelets. Proc Natl Acad Sci USA. 2005;102(28):9820-5.

23. Foo SS, Turner CJ, Adams S, Compagni A, Aubyn D, Kogata $\mathrm{N}$, et al. Ephrin-B2 controls cell motility and adhesion during blood-vessel-wall assembly. Cell. 2006;124(1):161-73.

24. Suenobu S, Takakura N, Inada T, Yamada Y, Yuasa H, Zhang $\mathrm{XQ}$, et al. A role of EphB4 receptor and its ligand, ephrinB2, in erythropoiesis. Biochem Biophys Res Commun. 2002;293(3):1124-31.

25. Ting MJ, Boyd AW. The role of Eph receptor tyrosine kinases and ephrin ligands in hematopoietic cell development and function. Open Hematol. 2008;2:103-10.

26. Ting MJ, Day BW, Spanevello MD, Boyd AW. Activation of ephrin A proteins influences hematopoietic stem cell adhesion and trafficking patterns. Exp Hematol. 2010;38(11):1087-98.

27. Wang Z, Miura N, Bonelli A, Mole P, Carlesso N, Olson DP, et al. Receptor tyrosine kinase, EphB4 (HTK), accelerates differentiation of select human hematopoietic cells. Blood. 2002;99(8):2740-7. 
28. Yu G, Luo H, Wu Y, Wu J. EphrinB1 is essential in T-cellT-cell co-operation during T-cell activation. J Biol Chem. 2004;279(53):55531-9.

29. Eaves C, Miller C, Cashman J, Conneally E, Petzer A, Zandstra P, et al. Hematopoietic stem cells: inferences from in vivo assays. Stem Cells. 1997;15(S2):1-5.

30. Miller J, McCullar V, Punzel M, Lemischka I, Moore K. Single adult human $\mathrm{CD} 34^{+} / \mathrm{Lin}^{-} / \mathrm{CD} 38^{-}$progenitors give rise to natural killer cells, B-lineage cells, dendritic cells, and myeloid cells. Blood. 1999;93(1):96-106.

31. Kiel MJ, Radice GL, Morrison SJ. Lack of evidence that hematopoietic stem cells depend on N-cadherin-mediated adhesion to osteoblasts for their maintenance. Cell Stem Cell. 2007;1(2):204-17.

32. Greenbaum A, Hsu YS, Day RB, Schuettpelz LG, Christopher MJ, Borgerding JN, et al. CXCL12 in early mesenchymal progenitors is required for haematopoietic stem-cell maintenance. Nature. 2013;495(7440):227-30. doi:10.1038/nature11926 ( 2013 03/14/print).

33. Ding L, Morrison SJ. Haematopoietic stem cells and early lymphoid progenitors occupy distinct bone marrow niches. Nature. 2013;495(7440):231-5. doi:10.1038/nature11885 (2013 03/14/ print).

34. Oguro H, Ding L, Morrison SJ. SLAM family markers resolve functionally distinct subpopulations of hematopoietic stem cells and multipotent progenitors. Cell Stem Cell. 2013;13(1):102-16.

35. Munoz JJ, Alfaro D, Garcia-Ceca J, Alonso-C LM, Jimenez E, Zapata A. Thymic alterations in EphA4-deficient mice. J Immunol. 2006;177(2):804-13.

36. Arvanitis DN, Jungas T, Behar A, Davy A. Ephrin-B1 reverse signaling controls a posttranscriptional feedback mechanism via miR-124. Mol Cell Biol. 2010;30(10):2508-17.

37. Luo $\mathrm{H}, \mathrm{Yu} \mathrm{G}, \mathrm{Wu} \mathrm{Y}, \mathrm{Wu} J$. EphB6 crosslinking results in costimulation of T cells. J Clin Invest. 2002;110:1141-50.

38. Sharfe N, Freywald A, Toro A, Dadi H, Roifman C. Ephrin stimulation modulates $\mathrm{T}$ cell chemotaxis. Eur $\mathrm{J}$ Immunol. 2002;32(12):3745-55.

39. Yu G, Luo H, Wu Y, Wu J. Ephrin B2 induces T Cell costimulation. J Immunol. 2003;171(1):106-14.

40. Aasheim HC, Munthe E, Funderud S, Smeland EB, Beiske K, Logtenberg T. A splice variant of human ephrin-A4 encodes a soluble molecule that is secreted by activated human B lymphocytes. Blood. 2000;95(1):221-30.

41. Prevost N, Woulfe D, Tanaka T, Brass LF. Interactions between Eph kinases and ephrins provide a mechanism to support platelet aggregation once cell-to-cell contact has occurred. Proc Natl Acad Sci USA. 2002;99(14):9219-24.

42. Ivanova NB, Dimos JT, Schaniel C, Hackney JA, Moore KA, Lemischka IR. A stem cell molecular signature. Science. 2002;298(5593):601-4.

43. Steidl U, Bork S, Schaub S, Selbach O, Seres J, Aivado M, et al. Primary human CD34+ hematopoietic stem and progenitor cells express functionally active receptors of neuromediators. Blood. 2004;104(1):81-8.

44. Nguyen TM, Arthur A, Panagopoulos R, Paton S, Hayball JD, Zannettino AC, et al. EphB4 expressing stromal cells exhibit an enhanced capacity for hematopoietic stem cell maintenance. Stem Cells. 2015;33(9):2838-49.

45. Gronthos S, Zannettino AC, Hay SJ, Shi S, Graves SE, Kortesidis A, et al. Molecular and cellular characterisation of highly purified stromal stem cells derived from human bone marrow. $\mathrm{J}$ Cell Sci. 2003;116:1827-35.

46. Sacchetti B, Funari A, Michienzi S, DiCesare S, Piersanti S, Saggio I, et al. Self-renewing osteoprogenitors in bone marrow sinusoids can organise a hematopoietic microenvironment. Cell. 2007;131:324-36.
47. Shi S, Gronthos S. Perivascular niche of postnatal mesenchymal stem cells in human bone marrow and dental pulp. J Bone Miner Res. 2003;18(4):696-704.

48. Zannettino ACW, Paton S, Kortesidis A, Khor F, Itescu S, Gronthos S. Human mulipotential mesenchymal/stromal stem cells are derived from a discrete subpopulation of STRO-1bright/ CD $34^{-} / \mathrm{CD} 45^{-} /$glycophorin-A-bone marrow cells. Haematologica. 2007;92(12):1707-8.

49. Friedenstein AJ, Piatetzky S, Petrakova KV. Osteogenesiss of in transplant of bone marrow cells. J Embryol Exp Morphol. 1966;16:381-90.

50. Friedenstein AJ, Petrakova KV, Kurolesova AL, Frolova GP. Heterotopic of bone marrow. Analysis of precursor cells for osteogenic and hematopoietic tissues. Transplantation. 1968;6(2):230-47.

51. Friedenstein AJ, Chailakhian RK, Laylykina K. The development of fibroblast colonies in monolayer cultures of guinea-pig bone marrow and spleen cells. Cell Tissue Kinet. 1970;3:393-403.

52. Friedenstein AJ, Chailakhyan RK, Latsinik NV, Panasyuk AF, Keiliss-Borok IV. Stromal cells responsible for transferring the microenvironment of the haematopoietic tissues. Cloning in vitro and retransplantation in vivo. Transplantation. 1974;17:331-40.

53. Short BJ, Brouard N, Simmons PJ. Prospective isolation of mesenchymal stem cells from mouse compact bone. Stem Cell Regen Med. 2009;482(5):259-68.

54. Lundberg P, Allison SJ, Lee NJ, Baldock PA, Brouard N, Rost S, et al. Greater bone formation of Y2 knockout mice is associated with increased osteoprogenitor numbers and altered $\mathrm{Y} 1$ receptor expression. J Biol Chem. 2007;282(26):19082-91.

55. Noll JE, Williams SA, Tong CM, Wang H, Quach JM, Purton LE, et al. Myeloma plasma cells alter the bone marrow microenvironment by stimulating the proliferation of mesenchymal stromal cells. Haematologica. 2014;99(1):163-71.

56. Winkler IG, Barbier V, Wadley R, Zannettino ACW, Williams S, Lévesque J. Positioning of bone marrow hematopoietic and stromal cells relative to blood flow in vivo: serially reconstituting hematopoietic stem cells reside in distinct nonperfused niches. Blood. 2010;116(3):375-85.

57. Irie N, Takada Y, Watanabe Y, Matsuzaki Y, Naruse C, Asano M, et al. Bidirectional signaling through ephrinA2-EphA2 enhances osteoclastogenesis and suppresses osteoblastogenesis. J Biol Chem. 2009;284(21):14637-44.

58. Martin TJ, Allan EH, Ho PWM, Gooi JH, Quinn JMW, Gillespie MT et al. Communication between ephrinB2 and EphB4 within the osteoblast lineage. In: Choi Y, editor. Osteoimmunology. Berlin: Springer; 2010. p 51-60.

59. Zhao C, Irie N, Takada Y, Shimoda K, Miyamoto T, Nishiwaki $\mathrm{T}$, et al. Bidirectional ephrinB2-EphB4 signaling controls bone homeostasis. Cell Metab. 2006;4(2):111-21.

60. Xing W, Kim J, Wergedal J, Chen ST, Mohan S. Ephrin B1 regulates bone marrow stromal cell differentiation and bone formation by influencing TAZ transactivation via complex formation with NHERF1. Mol Cell Biol. 2010;30(3):711-21.

61. Twigg SR, Rui K, Babbs C, Bochukova EG, Robertson SP, Wall SA, et al. Mutations of ephrin-B1 (EFNB1), a marker of tissue boundary formation, cause craniofrontonasal syndrome. Proc Natl Acad Sci USA. 2004;101:8652-7.

62. Coulthard MG, Morgan M, Woodruff TM, Arumugam TV, Taylor SM, Carpenter TC, et al. Eph/ephrin signaling in injury and inflammation. Am J Pathol. 2012;181(5):1493-503.

63. Pitulescu ME, Adams RH. Eph/ephrin molecules-a hub for signaling and endocytosis. Genes Dev. 2010;24(22):2480-92.

64. Wieland I, Jakubiczka S, Muschke P, Cohen M, Thiele H, Gerlach KL, et al. Mutations of the ephrin-B1 gene cause craniofrontonasal syndrome. Am J Hum Genet. 2004;74(6):1209-15. 
65. Bush JO, Soriano P. Ephrin-B1 forward signaling regulates craniofacial morphogenesis by controlling cell proliferation across Eph-ephrin boundaries. Genes Dev. 2010;24(18):2068-80.

66. Makarov R, Steiner B, Gucev Z, Tasic V, Wieacker P, Wieland I. The impact of CFNS-causing EFNB1 mutations on ephrin-B1 function. BMC Med Genet. 2010;11(1):98.

67. Allan EH, Häusler KD, Wei T, Gooi JH, Quinn JMW, CrimeenIrwin B, et al. EphrinB2 regulation by PTH and PTHrP revealed by molecular profiling in differentiating osteoblasts. J Bone Miner Res. 2008;23(8):1170-81.

68. Honczarenko M, Le Y, Swierkowski M, Ghiran I, Glodek AM, Silberstein LE. Human bone marrow stromal cells express a distinct set of biologically functional chemokine receptors. Stem Cells. 2006;24(4):1030-41.

69. Moore MAS. Hematopoietic stem cells. In: Rajasekhar VK, Vemuri MC, editors. Regulatory networks in stem cells. New York: Humana Press; 2009. p. 347-77.

70. Daar IO. Non-SH2/PDZ reverse signaling by ephrins. Semin Cell Dev Biol. 2012;23(1):65-74.

71. Lichterfield M, Martin S, Burkly L, Haas R, Kronenwett R. Mobilization of $\mathrm{CD}_{3} 4^{+}$haematopoietic stem cells is associated with a functional inactivation of the integrin very late antigen 4 . Br J Haematol. 2000;110:71-81.

72. Simmons PJ, Masinovsky B, Longenecker BM, Berenson R, Torok-Storb B, Gallatin WM. Vascular cell adhesion molecule-1 expressed by bone marrow stromal cells mediates the binding of hematopoietic progenitor cells. Blood. 1992;80(2):388-95.

73. Pasquale EB. Eph-ephrin promiscuity is now crystal clear. Nat Neurosci. 2004;7(5):417-8. doi:10.1038/nn0504-417.

74. Scadden DT. Nice neighborhood: emerging concepts of the stem cell niche. Cell. 2014;157(1):41-50.
75. Vail ME, Murone C, Tan A, Hii L, Abebe D, Janes PW, et al. Targeting EphA3 inhibits cancer growth by disrupting the tumor stromal microenvironment. Cancer Res. 2014;74(16):4470-81.

76. Janes PW, Slape CI, Farnsworth RH, Atapattu L, Scott AM, Vail ME. EphA3 biology and cancer. Growth Factors. 2014;32(6):176-89.

77. Keane N, Freeman C, Swords R, Giles FJ. EPHA3 as a novel therapeutic target in the hematological malignancies. Expert Rev Hematol. 2012;5(3):325-40.

78. Tomasevic N, Luehrsen K, Baer M, Palath V, Martinez D, Williams $\mathrm{J}$, et al. A high affinity recombinant antibody to the human EphA3 receptor with enhanced ADCC activity. Growth Factors. 2014;32(6):223-35.

79. Garcia-Gomez A, Sanchez-Guijo F, del Cañizo MC, San Miguel JF, Garayoa M. Multiple myeloma mesenchymal stromal cells: contribution to myeloma bone disease and therapeutics. World $\mathrm{J}$ Stem Cells. 2014;6(3):1803-12.

80. Pennisi A, Ling W, Li X, Khan S, Shaughnessy JD, Barlogie B, et al. The ephrinB2/EphB4 axis is dysregulated in osteoprogenitors from myeloma patients and its activation affects myeloma bone disease and tumor growth. Blood. 2009;114(9):1803-12.

81. Vandyke K, Chow AWS, Williams SA, To LB, Zannettino ACW. Circulating N-cadherin levels are a negative prognostic indicator in patients with multiple myeloma. $\mathrm{Br} \mathrm{J}$ Haematol. 2013;161(4):499-507.

82. Valverde-Franco G, Pelletier JP, Fahmi H, Hum D, Matsuo K, Lussier B, et al. In vivo bone-specific EphB4 overexpression in mice protects both subchondral bone and cartilage during osteoarthritis. Arthritis Rheum. 2012;64(11):3614-25. 